a course of treatment which has the effect of reducing the patient's strength, with the view of preventing inflammation, 2nd. The post-mortern examination does not commonly reveal much serious inflammatory mischief; sonetimes, indeed, as in Case 1, there appears to have been, what the symptoms would lead us to expect, rather a want of reparative force. 3rd. The movement of the patient requisite for the topical abstraction of blood is a serious objection to the practice, and the supine position proposed by $\mathrm{Mr}$. Crowfoot to obviate this difficulty would, I fear, in many cases involve others not less important. These remarks are intended to apply only to the einployment of blood-letting as a means of preventing inflammation in cases of fractured vertebræ, and have no reference to the treatment necessary, when symptoms of inflammation shall have arisen.

\section{A CASE OF SPONTANEOUS CURE OF HYDROCELE.}

By Frederick Cox, Esq., Surgeon, Welford.

TO THE EDITOR OF THE PROVINCIAL MEDICAL AND Sir, SURGICAL JOURNAL.

You will oblige me by inserting the following case, if you think it worthy a place in your Journal :-

Mr. - consulted me in the autumn of last year, for an inflamed testicle, which was treated in the usual way by leeches, cold lotions, \&c., and soon got better, a slight enlargement remaining. After a few weeks fluid became perceptible in the tunica vaginalis, and this went on increasing until a tolerably large hydrocele was produced. Early in February last, I removed the fluid by means of the trocar, but took no steps to effect a permanent cure. The fluid, as was to be expected, soon began ağain to accumulate, and in the month of April at least five or six ounces were in the sac. I saw Mr. - in the months of May and June, und each time found the water had sensibly decreased, and by the middle of July it was entirely gone ; the most minute examination failed in detecting the least appearance of fluid, nor has any been effused up to this time. Beyond a slight enlargement of the testis, and a little tenderness and occasional pain of that organ, the parts are now perfectly normal.

The occupation of my patient is of a most active character, requiring his presence in London twice a week, and subjecting him to much horse-exercise every day. He is rather intemperate in his habits. I mention these circumstances because they may be thought to have played a part in causing the absorption of the hydrocele.

Now, I must state, that no local remedies whatever had been employed in this case with the view of dispersing the affection; but $\mathrm{Mr}$. —— has been taking for more than a year, the jodide of potassium, with decoction of sarsaparilla, for secondary syphilitic symptoms. Whether the exhibition of these medicines had any effect in causing the absorption of the hydrocele, is a point I leave for your readers to speculate upon, merely stating my own opinion, which. is, that they were perfectly innocent of the cure. I am not aware that the iodide of potassium administered internally has any influence in causing the absorption of such serous effusions, whatever power it may have in removing glandular enlargements and the like. I look upon the employment of the remedies, and the absorption of the fluid as a mere coineidence, and not as cause and effect. My patient took the above medicine long before the hydrocele appeared, and during its production, and for some time before the tapping, iodine was freely used externally, as well as taken internally, with a view to its dispersion, but without the least beneficial result ; on the other hand, the fluid steadily increased under its use. I should rather look for the cure to have been effected by the active horseexercise and the over indulgence in stimulants. These combined would doubtless set up a brisk action in the tunica vaginalis and testis generally, and under such a condition of the organ, the absorption might reasonably be looked for, if it might be looked for under any circumstances, - of course I mean no remedies being used. Sir Benjamin Brodie has mentioned two unequivocal instances of spontaneous cure of hydrocele from inflammation of the tunica vaginalis accidentally taking place, and Dr. Watson narrates a case where rapid absorption followed a fit of drunkenness.

I cannot think the above an uninteresting case or one unworthy of publication; for at a recent trial, some dozen medical men were examined, (myself among the rest,) and the question was raised, whether hydrocele ever does become spontaneously absorbed. One gentleman of considerable experience and some eminence, declared he had never met with such a case, either in his practice or his reading, and that he had communicated with many of his professional friends, of good practice, but none had ever known of such an instance. Doubtless it is a rara avis, but not, I think, so much so as the declaration of the gentleman above alluded to would lead one to infer. I know of one other case of spontaneous absorption in my own neighbourhood, that occurred in the practice of my friend Mr. Marshall, of Moulton. In that instance, the fluid returned after a time, it may of course do so in mine if the sác be not obliterated; but as there has been more or less tenderness, and even pain occasionally for some time, that desirable end may have been attained. However that may be, it is sufficient, in a medico-legal point of view; (in which view it is to me most interesting, from the fact above alluded to, ) to be aware that the water, under some rare circumstances, does disappeas per se, and that it may remain absent for weeks and months.

I remain, Sir, Yours faithfully,

Welford, Oct. 22, 1846. FREDERICK COX.

\section{ILLUSTRATIONS OF THE PRACTICE OF 1. LINCOLNSHIRE BONE-SETTERS.}

TO THE EDITOR OF THE PROVINCIAL MEDICAL AND Sir,

If you consider the following cases, illustrating the practice of Lincolnshire bone-setters, of sufficient importance, please to insert them in the Journal.

Yours truly,

Long Sutton, Oct. 23, 1846. HENRY EWEN.

Case I.

October 22, 1836. I was requested by the Board of 
Guardians of the Holbeach Union to visit Isaac Vines, aged 2', an agricultural labourer, residing in Tydd Marsh, and report his state. His left thigh-bone had been fractured by a kick from a horse nearly eleven weeks previously, and during that time he had been under the care of $\mathrm{Mr}$. — , a bone-setter, residing at Wisbeach; the sane thigh had been fractured during the preceding year, and union took place in five weeks, under the treatment of the same person. I found the leg and foot excessively swollen; the limb was placed upon the heel on pillows; there was no splint nor firm support under the thigh; his general health was not good; his pulse was 108 ; and he complained of debility.

November 10th. I was requested to take charge of the case. I found the limb placed on a double inclined plane without any padding; a roller on the leg from the foot to the knee, and the swelling lessened in consequence. The femur was fractured obliquely from within downwards and outwards a little above the middle; the upper fragment drawn outwards; the lower upwards and inwards; the thigh is shortened three inches; no urion has taken place; general health better.

16th. Having obtained a mattress, and laths for the bed-stead, I placed the limb on an apparatus similar in principle to Amesbury's; the limb was easily extended to nearly its natural length; pads were so placed as to press the upper fragment inwards, and the lower outwards.

17 th. The limb rests easy on the apparatus. Ordered a mutton-chop and a pint of porter daily; tonic medicine; and an occasional aperient.

19 th. Is very comfortable; pulse 84 ; tongue clean. The straps over the thigh-splints were tightened.

January 17, 1837. The apparatus removed this day, when union of the fracture was found to have taken place. His general health very good.

In about three weeks after this date he was removed to his parish, near Oakham, in Rutlandshire. During the first few weeks after the thigh-splints were tightened he frequently experienced considerable pain at the seat of fracture; after the first month this ceased to trouble lim. I was careful not to disturb the splints more than two or three times during the whole nine weeks the apparatus was applied, and then merely to relieve a slight excoriation at the upper and inner part of the thigh caused by the inner splint, and to adjust. the padding so as to maintain the requisite pressure.

I saw this man a few months ago; he had walked from the vicinity of Oakham to this place, and called to express his thanks; the limb is somewhat shortened. The Board of Guardians refused to allow me any fee for the management of this case.

\section{Case II.}

Thomas Johnson, a labourer, rsiding at Tydd Gote, consulted me in the autumn of 1838 . About an hour before I saw him, the wheel of a drill had passed over bis face and fractured his jaw just anterior to the angle on the left side. A pasteboard splint and a roller were applied in the mode recommencled by Chapman in his "Atlas of Surgical Apparatus." Four days after the accident his fellow-labourers subscribed thirty shillings to enable him to place himself under the same bone-setter as in Case I.; but seeing that the case was rather serious, the party in question declined neddling with it. Two days after the patient obtained an order from the Union, and I continued to attend him; he required a good deal of attention during the first fortnight, as an abscess formed in the cheek, but ultimately he had a good recovery.

\section{Case III.}

January 5, 1840. I visited Mrs. Henry Smith, a middle-aged woman, the wife of a farmer, residing at Tydd Saint Giles. Five days previously she fell down some steps at Wisbeach and fractured the radius and ulna of the right arm a little above the wrist-joint. She placed herself under the care of the same bonesetter as in Case I. Splints were applied and cold lotion, and the patient reached her home the same night, a distance of nearly six miles from Wisbeach. When I saw her the finger and thumb and greater part of the hand were in a state of gangrene; the arm was much sivollen, and intensely inflamed; the hand and arm as high as the elbow were covered with turpentine dressings ; constitutional disturbance considerable. The arm was directed to be fomented with warm poppy fomentation, and linseed-meal poultices applied; saline medicine with antimony, and small doses of calonel and opium were prescribed.

6th. The arm is much easier, and the inflammation and swelling have diminished; the whole hand is gangrenous, and there is a red line of demarcation near the wrist, indicating the spot where separation of the dead parts from the living structures is about to take place. I advised amputation, but the patient refused to submit to an operation, and said "she would die with it on." I explained to her that although I considered an operation afforded her the best chance of recovery, it was very possible that separation of the dead parts might take place, and her life be preserved, but that the process would be slow, and attended with great suffering and hazard. As the patient refused all medicine, I was told that I need not repeat my visits.

Six months afterwards I saw this person pretty well recovered, and with a neat stump, the dead parts haring separated by the natural processes.

\section{Casa IV.}

May 16, 1827. I assisted Mr. Cook, of Gainsborough, to amputate the thigh of $\mathrm{Mr}$. Whitelouse, aged 53, a farmer, residing at Springthorpe, who had been the subject of diseased knee-joint six years. During the early part of his illness he was under the care of $\mathrm{Mr}$. -, a famous bone-setter, residing at Coningsby, who treated the case as for dislocation, and greatly aggravated the sufferings of the patient by his rude manipulations. The semilunar cartilages, and the cartilages covering the condyles of the femur and hend of the tibia were destrayed; the internal condyle and corresponding surface of the tibia were carious; the cartilages covering the inner surface of the patella, and that covering the corresponding articular surface of the femur were undergoing the ulcerative process. The patient had a good recovery. 